\title{
Initial Growth of Seedlings of Mountain Laurel as Influenced by Day/Night Temperature
}

\author{
Asiah A. Malek ${ }^{1}$, Frank A. Blazich², Stuart L. Warren ${ }^{3}$, and James E. Shelton ${ }^{4}$ \\ Department of Horticultural Science, North Carolina State University, Raleigh, NC 27695-7609
}

Additional index words. Kalmia latifolia, native plants, optimum temperature

\begin{abstract}
Seedlings of mountain laurel (Kalmia latifolia L.) were grown for 16 weeks under long-day conditions with days at 18, 22, 26, or 30C for 9 hours in factorial combination with nights at 14, 18, 22, or 26C for 15 hours. Total plant dry weight, top dry weight, and dry weights of leaves, stems, and roots were influenced by day and night temperatures. The night optimum for all dry weight categories was 22C. Dry matter production was lowest with nights at 14C. Total plant dry weight and dry weights of tops, leaves, and stems were maximized with days at $26 \mathrm{C}$, but for roots the optimum was 22C. Dry weight accumulation was lower with days at 18 or 30C. Responses of leaf area were similar to that of total plant dry weight, with optimum days and nights at 26 and $22 \mathrm{C}$, respectively. Within the optimal day/night temperature range of $22-26 / 22 \mathrm{C}$ for dry weights, there was no evidence that alternating temperatures enhanced growth. Shoot : root ratios (top dry weight : root dry weight) increased with day temperatures up to $30 \mathrm{C}$ and were highest with nights at 14 or $26 \mathrm{C}$. Leaf weight ratio (leaf dry weight : total plant dry weight) decreased with increasing night temperature, and increased curvilinearly in response to day temperature with the minimum at $26 \mathrm{C}$. Stem weight ratio (stem dry weight : total plant dry weight) increased with increasing day or night temperature. Root weight ratio (root dry weight : total plant dry weight) was highest with nights at 18 or $22 \mathrm{C}$ and decreased with days $>22 \mathrm{C}$. Net leaf photosynthetic rate was maximized with days at $26 \mathrm{C}$.
\end{abstract}

Mountain laurel is an indigenous, broad-leaved evergreen shrub occupying a range extending from southern Maine; west through southern New York to central Ohio; south to southern Mississippi, Alabama, and Georgia; and northwestern Florida (Jaynes, 1988). It blooms from March to July, depending on location (Olson and Barnes, 1974), and is an outstanding landscape species.

Interest and demand for mountain laurel have steadily increased in recent years, but landscape-size plants have not been readily available. A contributing factor is slow growth. It takes 2 to 3 years to produce a plant $7.5 \mathrm{~cm}$ tall when propagated by seed outdoors, but less time is required under greenhouse conditions (Jaynes, 1988). Techniques that increase plant size during the first few months also tend to reduce time to flowering. Subjecting seeds following sowing to $2000 \mathrm{ppm} \mathrm{CO}_{2}$ for 7 weeks increases germination rate and subsequent seedling growth (Jaynes, 1988). However, $\mathrm{CO}_{2}$ enrichment alone will not stimulate growth; light, fertility, and temperature must be equally favorable (Jaynes, 1988).

In a preliminary study on the influence of temperature and photoperiod on growth of mountain laurel, seedlings were placed for 16 weeks under short-day (9-h photoperiod daily) or longday (9-h photoperiod +3 -h night interruption daily from 11:00 PM to 2:00 AM) conditions with 9-h day/15-h night cycles at 22/ 18, 26/22, and 30/26C (Malek et al., 1990). Plants grown under long days produced more top growth than those exposed to short

Received for publication 12 Nov. 1991. Accepted for publication 11 Mar. 1992. This paper is based on a portion of a thesis to be submitted by A.A.M. in partial fulfillment of the requirements for the $\mathrm{PhD}$ degree. This research was funded by the North Carolina Agricultural Research Service (NCARS), Raleigh, NC 276957643. Assistance of William M. Reece, Juan R. Acedo, and the staff of the Southeastern Plant Environment Laboratory (Phytotron), Raleigh, N.C., is gratefully acknowledged. Use of trade names in this publication does not imply endorsement by the NCARS of the products named nor criticism of similar ones not mentioned. The cost of publishing this paper was defrayed in part by the payment of page charges. Under postal regulations, this paper therefore must be hereby marked advertisement solely to indicate this fact.

'Graduate Student

${ }^{2}$ Professor.

${ }^{3}$ Associate Professor.

${ }^{4}$ Associate Professor, Dept. of Soil Science. days for all three temperature combinations. Long-day conditions, therefore, appear to accelerate growth of mountain laurel.

Little has been reported on the influence of temperature on growth of mountain laurel. The few previous temperature studies associated with mountain laurel dealt with seed germination (Jaynes, 1971; Malek et al., 1989). Temperature undoubtedly affects growth as well. However, determination of an optimum temperature for growth is complex because it may change not only with stage of plant development, but also with the growth measurements used (Haroon et al., 1972; Hellmers, 1966; Hinesley, 1981). For example, Fraser fir [Abies fraseri (Pursh) Poir.] has different temperature optima for root, shoot, and total plant dry weights (Hinesley, 1981). Malek et al. (1992) found a common optimum day/night temperature for root, leaf, top, and total plant dry weight, but different temperature optima for leaf area and stem dry weight in seedlings of flame azalea [Rhododendron calendulaceum (Michx.) Torr].

To better understand the growth response of mountain laurel to temperature, there was an obvious need for research. Such information could be useful in developing production schedules to optimize growth. Therefore, the present study was conducted to examine the effects of selected day/night temperatures on initial vegetative growth of seedlings of mountain laurel.

\section{Materials and Methods}

On 13 Nov. 1986, mature seed capsules were collected from a native stand of open-pollinated plants growing in Avery County, N.C., at an elevation of $923 \mathrm{~m}$. Capsules were stored in a paper bag at $20 \mathrm{C}$ for 21 days. Seeds were then removed from the capsules and stored at a moisture content of $5 \%$ in a sealed bottle at $4 \pm 1 \mathrm{C}$. Moisture content of the seeds was determined by calculating the mean moisture content of six 100-seed samples following drying at $105 \mathrm{C}$ for $24 \mathrm{~h}$.

Seeds were removed from storage on 19 Sept. 1988 and surface-sown in flats containing a medium of 4 pine bark : 1 peat $(\mathrm{v} / \mathrm{v})$. Flats were placed under intermittent mist (Mist-A-Matic, E.C. Geiger, Harleysville, Pa.) in a growth room at day/night cycles of $\approx 24 / 18 \mathrm{C}$ with a daily 18 -h photoperiod (6:00 AM to 12:00 PM) provided by cool-white fluorescent lamps. The lamps provided a photosynthetic photon flux (PPF) of $260 \mu \mathrm{mol} \cdot \mathrm{m}^{-2} \cdot \mathrm{s}^{-1}$ 
plus photomorphogenic radiation (PR) of $5.7 \mathrm{~W} \cdot \mathrm{m}^{-2}$. These and other light measurements were recorded with a cosine corrected LI-COR LI-185 quantum/radiometer/photometer (LI-COR, Lincoln, Neb.).

Following germination, seedlings were fertilized weekly with 180 ppm N from a $15 \mathrm{~N}-20 \mathrm{P}-4 \mathrm{~K}$ water soluble fertilizer (Rhododendron Special; Grace/Sierra, Fogelsville, Pa.) also containing $200 \mathrm{ppm} \mathrm{CaCl}_{2}$ and $75 \mathrm{ppm} \mathrm{MgSO}_{4}$. When seedlings were $\approx 2$ $\mathrm{cm}$ tall, they were transplanted individually into 1-liter containers with arcillite, a calcined clay as the medium. Arcillite was selected as a medium because it allows recovery of intact root systems at harvest (Hiller and Koller, 1979). Plants were grown under natural irradiance from 800 AM to 5:00 $\mathrm{PM}$ in a greenhouse maintained at day/night cycles of $\approx 24 / 16 \mathrm{C}$. From 11:00 PM to 2:00 AM daily, plants received a night interruption from incandescent lamps which provided a PPF of 3.6 $\mu \mathrm{mol} \cdot \mathrm{m}^{-2} \cdot \mathrm{s}^{-1}$ plus PR of $0.7 \mathrm{~W} \cdot \mathrm{m}^{-2}$ as measured at the top of the containers. Plants were fertilized weekly as previously described. Ten days after potting, plants were pruned to three leaves to encourage branching.
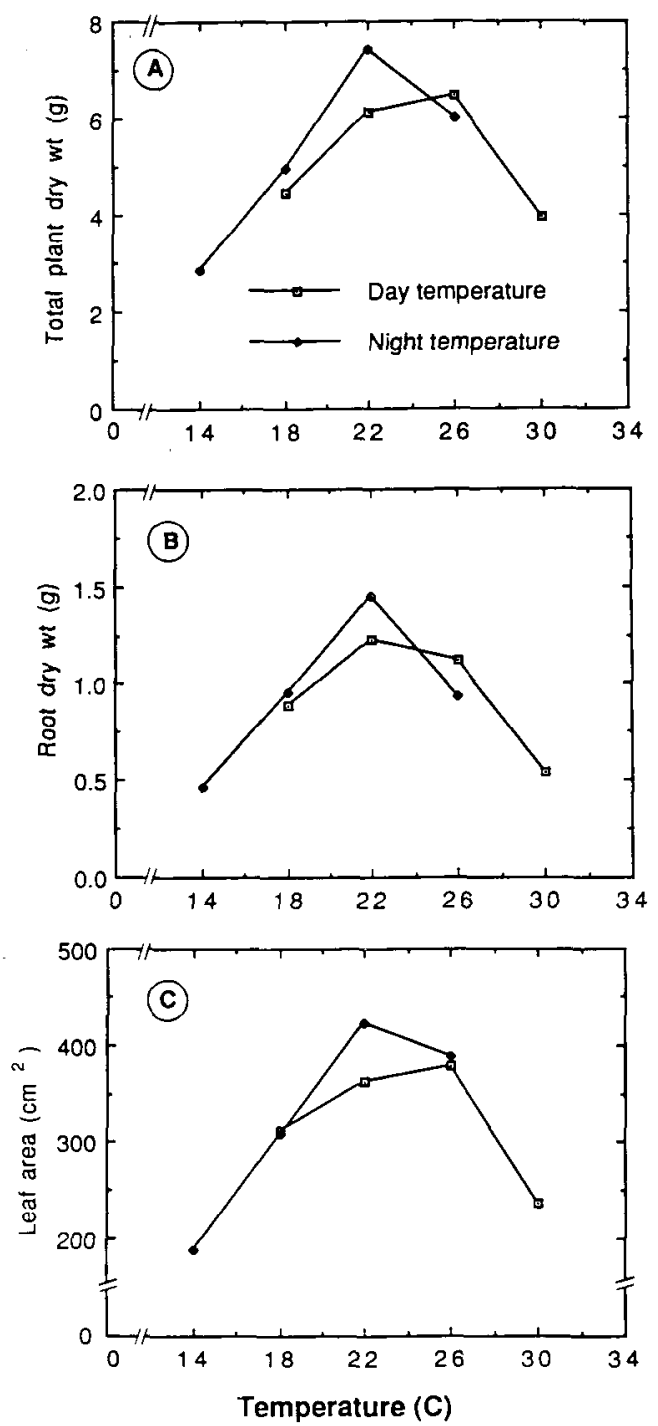

Fig. 1. Effects of day temperature (averaged over all night temperatures) and night temperature (averaged over all day temperatures) on initial growth of seedlings of mountain laurel: (A) total plant dry weight, (B) root dry weight, and (C) leaf area. Each datum is the mean for 36 observations.
On 2 June 1989, plants were transferred to the Southeastern Plant Environment Laboratory and the various temperature regimes were initiated the following day in controlled-environment A-chambers (Downs and Thomas, 1983). The study was a $4 \times 4$ factorial in a completely random design with nine single-plant replications. The two main factors were four day temperatures $(18,22,26$, and 30C) in factorial combination with four night temperatures $(14,18,22$, and 26C). Day temperatures were maintained for $9 \mathrm{~h}$ each day and coincided with the daily high irradiance light period. Temperatures were maintained within $\pm 0.25 \mathrm{C}$ of the set point. Plants were moved between chambers at 8:00 AM and 5:00 PM daily to maintain appropriate day/night temperatures. Relative humidity was $>70 \%$. Carbon dioxide concentration was 300 to $400 \mathrm{ppm}$.

During the 9-h high irradiance light period, chambers used a combination of cool-white fluorescent and incandescent lamps that provided a PPF of $642 \mu \mathrm{mol} \cdot \mathrm{m}^{-2} \cdot \mathrm{s}^{-1}$ plus PR of $8 \mathrm{~W} \cdot \mathrm{m}^{-2}$. Incandescent lamps providing a PPF of $44 \mu \mathrm{mol} \cdot \mathrm{m}^{-2} \cdot \mathrm{s}^{-1}$ plus PR of $6.7 \mathrm{~W} \cdot \mathrm{m}^{-2}$ were used to interrupt the dark periods between 11:00 PM and 2:00 AM daily.

Initially, plants were fertilized twice weekly (Tuesday and Friday) with the standard Phytotron nutrient solution (Downs and Thomas, 1983). Beginning on week 6, fertilization was three times weekly (Monday, Wednesday, and Friday). Plants were watered with deionized water on the remaining days.

At week 14, leaf gas exchange was measured with a LI-COR LI-6200 closed portable infrared gas exchange system between 12:00 and 3:00 PM. Photosynthetically active radiation, air and leaf temperatures, and relative humidity inside-the leaf chamber were measured concurrently with gas exchange. Net photosynthetic rate was calculated using the LI-COR 6200 measurements. An attached leaf was placed in a 1-liter $\left(1149-\mathrm{cm}^{3}\right)$ chamber for $20 \mathrm{sec}$. Vapor pressure deficits within the chamber at $18,22,26$, and $30 \mathrm{C}$ were $0.92,1.20,1.31$, and $1.71 \mathrm{kPa}$, respectively. Measurement commenced immediately after a reduction in $\mathrm{CO}_{2}$ concentration occurred. Data were recorded on three plants per treatment, and three measurements (subsamples) were taken from the most recently matured leaves on each plant.

The study was terminated 16 weeks after initiation. Plants were harvested and divided into leaves, stems, and roots that were dried at $70 \mathrm{C}$ for $72 \mathrm{~h}$ and weighed. Before drying of the leaves, their total area was measured with a LI-COR LI-3100 leaf area meter. Leaf, stem, and root dry weights were used to calculate the following: total plant dry weight (sum of leaf, stem, and root dry weight); top dry weight (sum of leaf and stem dry weight); shoot : root ratio (top dry weight : root dry weight); leaf weight ratio (leaf dry weight : total plant dry weight); stem weight ratio (stem dry weight : total plant dry weight); and root weight ratio (root dry weight : total plant dry weight). Data also included leaf area ratio (total leaf area : total plant dry weight) and specific leaf area (total leaf area : leaf dry weight). Data were subjected to analysis of variance procedures and regression analysis.

\section{Results}

The effects of day and and night temperature on dry matter production were independent. There were no significant interactions between day and night temperature for any dry weight category.

Total plant dry weight (Fig. 1A) was lowest at nights of $14 \mathrm{C}$ and increased with night temperatures, the maximum occurring at $22 \mathrm{C}$. Response of top dry weight, dry weights of leaves and stems (data not presented), and root dry weight (Fig. 1B) to 
Table 1. Growth responses of seedlings of mountain laurel to selected day/night temperatures.

\begin{tabular}{lcccccc}
\hline \hline & \multicolumn{6}{c}{ Variablez } \\
\cline { 2 - 7 } Growth characteristic & D & DL & DQ & N & NL & NQ \\
\hline Dry weight & $*$ & NS & $* *$ & $* *$ & $* *$ & $*$ \\
$\quad$ Total plant & $*$ & NS & $*$ & $* *$ & $* *$ & $*$ \\
Top & $*$ & NS & $*$ & $* *$ & $* *$ & $*$ \\
Leaf & $*$ & NS & $*$ & $* *$ & $* *$ & NS \\
Stem & $*$ & $*$ & $* *$ & $* *$ & $* *$ & $* *$ \\
Root & $*$ & NS & $*$ & $* *$ & $* *$ & $*$ \\
Leaf area & $* *$ & $* *$ & $* *$ & $*$ & NS & $* *$ \\
Shoot : root ratio & $*$ & NS & $*$ & $*$ & $*$ & $*$ \\
Leaf weight ratio & $* *$ & $* *$ & NS & $* *$ & $* *$ & NS \\
Stem weight ratio & $* *$ & $* *$ & $*$ & $*$ & NS & $* *$ \\
Root weight ratio & & & & & & \\
Net leaf & $*$ & NS & $*$ & NS & NS & NS \\
photosynthetic rate & $*$ & & NS & & \\
Leaf area ratio & NS & & & NS & & \\
Specific leaf area & NS & & &
\end{tabular}

${ }^{2} \mathrm{D}=$ day temperature, $\mathrm{DL}=$ day temperature (linear), $\mathrm{DQ}=$ Day temperature (quadratic), $\mathrm{N}=$ night temperature, $\mathrm{NL}=$ night temperature (linear), NQ = night temperature (quadratic).

ss, $*$,** Nonsignificant or significant at $\mathrm{P}=0.05$ or 0.01 , respectively.

night temperature was similar to that of total plant dry weight (Fig. 1A). All dry weight responses showed a clearly defined optimum night temperature of $22 \mathrm{C}$.

Days at 22 to $26 \mathrm{C}$ favored dry matter production. Optimum day temperature for total plant dry weight (Fig. 1A), top dry weight, and dry weights of leaves and stems (data not presented) was 26C, but for root dry weight (Fig. 1B) it was 22C. Dry weight accumulation was lower with days at 18 and 30C.
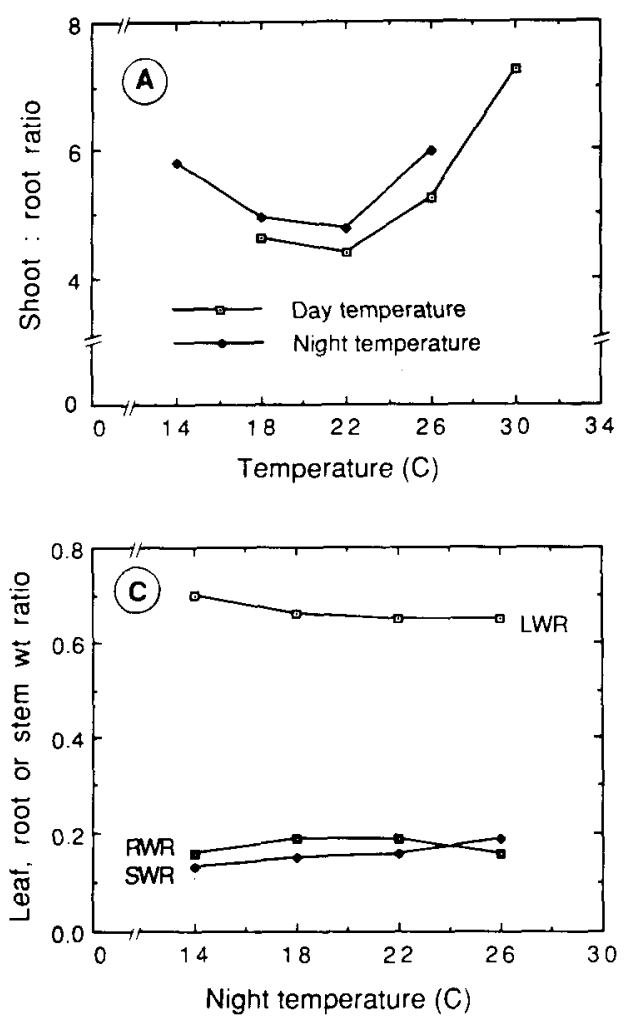

Response of leaf area (Fig. 1C) to day/night temperature was similar to that of total plant dry weight (Fig. 1A). Optimum night temperature for leaf area development was $22 \mathrm{C}$, and the day optimum was 22 to $26 \mathrm{C}$ (Fig. 1C). There was no significant day/night temperature interaction.

Night temperature had a significant quadratic effect on shoot : root ratio (Table 1), with the highest values occurring at 14 and 26C (Fig. 2A). Shoot : root ratios increased rapidly as day temperatures approached 30C (Fig. 2A).

Leaf weight ratio was consistently higher than either stem weight and root weight ratio throughout the whole range of day and night temperatures (Fig. $2 \mathrm{~B}$ and $\mathrm{C}$ ). The effects of day and night temperatures on these data were independent. Leaf weight ratio decreased slightly with increasing night temperature (Fig. 2C) and increased curvilinearly in response to day temperature with the minimum at 26C (Fig. 2B). Stem weight ratio increased linearly, but only slightly, with increasing day (Fig. 2B) or night temperature (Fig. 2C). The effect of night temperature on root weight ratio was quadratic (Table 1) with the highest ratios at 18 and $22 \mathrm{C}$, but the overall change with temperature was minimal (Fig. 2C). Root weight ratio decreased slightly with days $>22 \mathrm{C}$ (Fig. 2B).

Net leaf photosynthetic rate was quadratic, with maximum values with days at 26C (Fig. 2D). Neither day nor night temperature affected leaf area ratio or specific leaf area during the first 16 weeks of growth (Table 1).

\section{Discussion}

All dry weights were higher with the night temperature in the range of 14 to $22 \mathrm{C}$ (Fig. $1 \mathrm{~A}$ and $\mathrm{B}$ ). Total plant dry weight at $22 \mathrm{C}$ was $250 \%$ higher than that at $14 \mathrm{C}$ (Fig. 1A). With nights
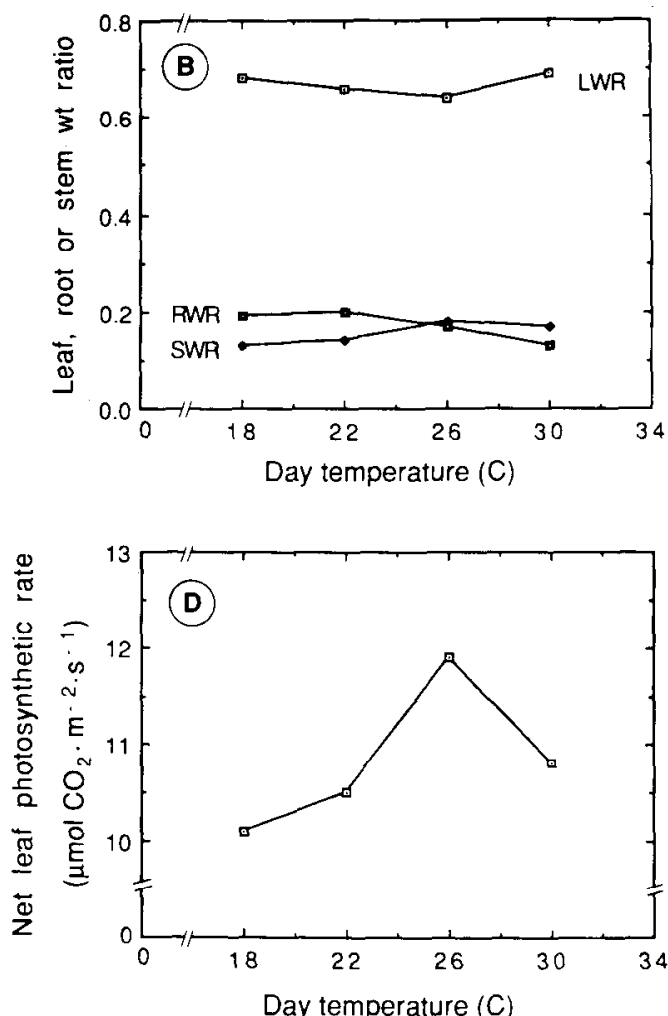

Fig. 2. Effects of day temperature (averaged over all night temperatures) and night temperature (averaged over all day temperatures) on initial growth of seedlings of mountain laurel: (A) shoot : root ratio; (B) leaf weight ratio (LWR), stem weight ratio (SWR), or root weight ratio (RWR) as a function of day temperature; (C) night temperature; and (D) net leaf photosynthetic rate as influenced by day temperature. In (A-C), each datum is the mean for 36 observations. In (D), each datum is the mean for 12 observations. 
at 26C, dry weight accumulation decreased noticeably (Fig. 1 A and B). Presumably, higher night temperatures resulted in greater loss of respiratory $\mathrm{CO}_{2}$, which reduced dry weight accumulation (Kramer and Kozlowski, 1979).

Root growth was apparently more sensitive to high day temperatures than top growth. For example, with days at 18 or $30 \mathrm{C}$, top dry weight was similar (data not presented), but root dry weight was lower at $30 \mathrm{C}$ than at $18 \mathrm{C}$ (Fig. 1B). Hence, prolonged exposure to high day temperatures could eventually lower seedling quality due to reduced root growth. High day temperatures also reduced root dry weight of flame azalea (Malek et al., 1992) and Fraser fir (Hinesley, 1981).

Within the optimal day/night range of 22-26/22C for dry weight data, there was no evidence alternating temperatures enhanced growth. Leaf, stem, root, top, and total plant dry weight were about equal and maximal at $22 / 22 \mathrm{C}$ and $26 / 22 \mathrm{C}$ (data not presented). Similarly, no evidence has been found for optimal thermoperiodicity in total plant dry weight of seedlings of flame azalea (Malek et al., 1992).

The response pattern of total plant dry weight (Fig. 1A) to the various temperature regimes was closely related to leaf area (Fig. 1C). This finding agrees with those of Dale (1964) who reported that in the vegetative stage, dry matter production was strongly associated with leaf area development. The growth rate of young plants depends strongly on the amount of light intercepted by leaves (De Koning, 1988).

Throughout the whole temperature range, leaf weight ratio was higher than either stem weight or root weight ratios, indicating that during initial seedling growth, dry matter distribution favored leaves. For seedlings of mountain laurel, grown at days of 18 and $22 \mathrm{C}, 66 \%$ of total dry matter was leaves compared to $20 \%$ in roots and $14 \%$ in stems (Fig. 2B). Proportions in roots and stems were equal at 26C (Fig. 2B). At days of 30C, leaf weight ratio increased and root-weight ratio decreased, indicating leaf growth was enhanced at the expense of roots. The opposite was true for nights of 14 and $18 \mathrm{C}$, where dry matter distribution favored roots at the expense of leaves (Fig. 2C). Nights at 26C favored an increase in the proportion of stems to roots.

Net leaf photosynthetic rate (Fig. 2D) and total plant dry weight (Fig. 1A) were highest at days of $26 \mathrm{C}$. In general, it is difficult to correlate photosynthetic rates and growth (Potter and Jones, 1977). With mountain laurel, however, the two variables were maximized at the same day temperature.

\section{Literature Cited}

Dale, J.E. 1964. Some effects of alternating temperature on the growth of French bean plants. Ann. Bot. (NS) 28:127-135.

De Koning, A.N.M. 1988. The effect of different day/night temperature regimes on growth, development and yield of glasshouse tomatoes. J. Hort. Sci. 63:465-471.

Downs, R.J. and J.F. Thomas. 1983. Phytotron procedural manual for controlled environment research at the Southeastern Plant Environment Laboratory. N.C. Agr. Res. Serv. Tech. Bul. 244 (Revised).

Haroon, M., R.C. Long, and J.A. Weybrew. 1972. Effect of day/night temperature on factors associated with growth of Nicotiana tubacum L. in controlled environments. Agron. J. 64:509-515.

Hellmers, H. 1966. Temperature action and interaction of temperature regimes in the growth of red fir seedlings. Forest Sci. 12:90-96.

Hiller, L.K. and K.C. Keller. 1979. Potato growth responses in arcillite and sand. HortScience 14:534-536.

Hinesley, L.E. 1981. Initial growth of Fraser fir seedlings at different day/night temperatures. Forest Sci. 27:545-550.

Jaynes, R.A. 1971. Seed germination of six Kalmia species. J. Amer. Soc. Hort. Sci. 96:668-672.

Jaynes, R.A. 1988. Kalmia, the laurel book II. Timber Press, Portland, Ore.

Kramer, P.J. and T.T. Kozlowski. 1979. Physiology of woody plants. Academic Press, New York.

Malek, A.A., F.A. Blazich, S.L. Warren, and J.E. Shelton. 1989. Influence of light and temperature on seed germination of mountain laurel. J. Environ. Hort. 7:161-162.

Malek, A.A., F.A. Blazich, S.L. Warren, and J.E. Shelton. 1990. Growth response of mountain laurel as influenced by temperature and photoperiod. Proc. Southern Nurserymen's Assn. Res. Conf., 35th Annu. Rpt. p. 75.

Malek, A.A., F.A. Blazich, S.L. Warren, and J.E. Shelton. 1992. Initial growth of seedlings of flame azalea in response to day/night temperature. J. Amer. Soc. Hort. Sci. 117:216-219.

Olson, D.F., Jr. and R.L. Barnes. 1974. Kalmia latifolia L. Mountainlaurel, p.470-471. In: C.S. Schopmeyer (Tech. Coordinator). Seeds of woody plants in the United States. Agr. Hdbk. 450. U.S. Dept. Agr. Forest Serv., Washington, D.C.

Potter, J.R. and J.W. Jones. 1977. Leaf area partitioning as an important factor in growth. Plant Physiol. 59:10-14. 